\title{
HIV-1 recombinants with multiple parental strains in low-prevalence, remote regions of Cameroon: Evolutionary relics?
}

\author{
Jean K Carr ${ }^{* 1}$, Nathan D Wolfe2, Judith N Torimiro3,4, Ubald Tamoufe5, E Mpoudi-Ngole55, Lindsay Eyzaguirre1, \\ Deborah L Birx ${ }^{6}$, Francine E McCutchan ${ }^{7}$ and Donald S Burke ${ }^{8}$
}

\begin{abstract}
Background: The HIV pandemic disseminated globally from Central West Africa, beginning in the second half of the twentieth century. To elucidate the virologic origins of the pandemic, a cross-sectional study was conducted of the genetic diversity of HIV-1 strains in villagers in 14 remote locations in Cameroon and in hospitalized and STI patients. DNA extracted from PBMC was PCR amplified from HIV $(+)$ subjects. Partial pol amplicons $(N=164)$ and nearly full virus genomes ( $N=78$ ) were sequenced. Among the 3956 rural villagers studied, the prevalence of HIV infection was 4.9\%; among the hospitalized and clinic patients, it was 8.6\%.

Results: Virus genotypes fell into two distinctive groups. A majority of the genotyped strains (109/164) were the circulating recombinant form (CRF) known to be endemic in West Africa and Central West Africa, CRF02_AG. The second most common genetic form (9/164) was the recently described CRF22_01A1, and the rest were a collection of 4 different subtypes (A2, D, F2, G) and 6 different CRFs (-01, $-11,-13,-18,-25,-37)$. Remarkably, 10.4\% of HIV-1 genomes detected (17/164) were heretofore undescribed unique recombinant forms (URF) present in only a single person. Nearly full genome sequencing was completed for 78 of the viruses of interest. HIV genetic diversity was commonplace in rural villages: 12 villages each had at least one newly detected URF, and 9 villages had two or more.

Conclusions: These results show that while CRF02_AG dominated the HIV strains in the rural villages, the remainder of the viruses had tremendous genetic diversity. Between the trans-species transmission of $\mathrm{SIV}_{\mathrm{cpz}}$ and the dispersal of pandemic HIV-1, there was a time when we hypothesize that nascent HIV-1 was spreading, but only to a limited extent, recombining with other local HIV-1, creating a large variety of recombinants. When one of those recombinants began to spread widely (i.e. became epidemic), it was recognized as a subtype. We hypothesize that the viruses in these remote Cameroon villages may represent that pre-epidemic stage of viral evolution.
\end{abstract}

\section{Background}

The geographic location of the origin of the HIV-1 pandemic is Central West Africa, where cross-species transmission of $\mathrm{SIV}_{\mathrm{cpz}}$ occurred from chimpanzee (Pan troglodytes troglodytes) to human [1-3]. From that transmission event the virus adapted into group M HIV-1 and gradually spread throughout the world. The genetic forms of HIV-1 currently present in Central West Africa,

\footnotetext{
* Correspondence: jecarr@ihv.umaryland.edu

1 Institute of Human Virology, Univ. of Maryland School of Medicine, Baltimore, MD, USA

Full list of author information is available at the end of the article
}

ground zero of the pandemic, may shed light on those early events.

Characterization of HIV-1 genetic diversity in different regions of the world is a challenging, on-going effort. Phylogenetic analyses of viral sequences have revealed distinct monophyletic clusters of strains called subtypes. There are now 9 official subtypes, and over 45 validated circulating recombinant forms (CRF) http:// www.hiv.lanl.gov/, and they exist in different patterns in various regions of the world. These patterns have been moderately well described, with strains from most countries now characterized to some degree or another. Cameroon is a location where the genetic diversity has been 
repeatedly studied; there have been at least 8 scientific reports of the genetic subtypes in Cameroon since 2005 [4-12]. The reason for this intense interest is that the HIV epidemic in Cameroon presents a paradoxical picture: the prevalence of infection is not high by African standards $(<10 \%$ in rural areas), yet the genetic diversity, including multiple recombinants of complex structure, is extremely high. While all of these studies have reported CRF02_AG as the most prevalent single genetic form in circulation, with estimates ranging from $45 \%$ to $61 \%$, the remaining strains have consisted of an array of other genetic forms, both classifiable and not [4-13]. Because of this genetic diversity, partial genome sequencing of relatively small sample sets has hampered the description of the epidemic fully. This report presents the genetic subtypes of more strains from rural Cameroon than have previously been reported, using nearly full genome sequencing to more completely describe the many unique recombinant forms (URF).

\section{Results}

\section{Partial Pol Analysis}

There were 164 HIV-1 strains characterized by partial pol sequencing out of a possible 178 . Most of the strains $\{126$ (76.8\%)\} were collected from 14 rural villages, where the prevalence of infection ranged from $1.9 \%$ to $7.5 \%$, though there was one site with a prevalence of $16.3 \%$. The geographic location of the study sites, identified by 2-letter code, is shown in Figure 1. In addition to samples from the rural villages, 26 strains from STI out-patients or general medicine in-patients were characterized, among whom the prevalence of infection was $8.6 \%$. Finally, 12 strains were examined from discarded blood units from the blood bank in Yaounde, the capital of Cameroon. No non-group $M$ strains were found.

Phylogenetic analysis of the partial pol sequences showed that the majority (66.5\%) clustered with CRF02_AG (Figure 2, panels A/B). Bootstrap analysis of the clusters was performed after the exclusion of URF, and significant bootstrap support (>70\%) was present for the strains highlighted in the figure. The next most common genetic form, present in $5.5 \%$ of the strains, was CRF22_01A1. This CRF is a recombinant between subsubtype A1 and CRF01_AE. Like CRF01_AE, CRF22_A101 is sub-subtype A1 in the pol region of the genome, but each of the CRFs (-01 and -22) form separate clusters within sub-subtype A1 that are distinct from each other, reflecting the different A1 strains that were parental to the different CRFs (Figure 2A). In addition, there were 10 more genetic forms identified: subtypes $D$ and G, sub-subtypes A2 and F2 plus CRFs -01, -11, -13, $18,-25$ and -37 . About ten percent of the strains, however, could only be described as a wide variety of unique recombinant forms (URF). On the phylogenetic tree, they are scattered throughout the tree, reflecting their varied structure (Figure 2A). In addition to the subtypes and CRF listed already, these recombinants included those having regions from subtypes $\mathrm{C}, \mathrm{H}$ and CRF09_cpx as well as regions that were unclassifiable.

The prevalence of the various genetic forms in the different rural sites is displayed in Figure 3, along with the overall prevalence at the site. The prevalence in the rural villages ranged from $2 \%$ to $16 \%$, and the proportion of the strains that were URF ranged from $0 \%$ to $44 \%$. Two sites (ND and BA) had no URFs, while others had 3 or more different ones (NG, LE, NJ and KO). There was no correlation, positive or negative, between the prevalence of infection and the proportion that were URF.

\section{Nearly Full Genome Analysis}

Full genome analysis of a subset of the CRF02_AG strains and most of the non-CRF02_AG strains was performed. There were 78 full genomes completed in all, and of these 23 were URF. The diversity of forms is tremendous, even when the prevalence of infection is low (Figure 4). Diagrams of the subtype structure of the 23 URF that were sequenced in full for this study show that more than 10 different subtypes or CRF are included in the strains, plus regions that are impossible to classify (Figure 4). Presumably some of those regions are either new subtypes or CRF that have not yet been identified. One of the most striking of the sites is Lomie, where the prevalence is $4.6 \%$ but there were 3 different unrelated URF containing 7 different parental strains between the 3 of them; even a passing glance can detect the lack of relatedness between the different URF from that site. At only one site (NG) were there two complex URFs with the same structure, suggesting transmission linkage. Demographic information suggested that they were married, over 50 years of age, and self-described as monogamous.

Significant hypermutation was observed in $14.1 \%$ of the full genomes, and another $16.7 \%$ were otherwise defective. Most of the hypermutated strains were classified using Hypermut http://www.hiv.lanl.gov/[14], but a few were only partially hypermutated and were discovered by the characteristic G-to-A mutations. From the context of the hypermutations, APOBEC3G is the likely enzyme responsible. In one case, a hypermutated strain also had a 36 aa deletion in the vif gene, suggesting that, for that individual, APOBEC3G was unimpeded by vif. A little over half of the hypermutated strains were URF (6/11, 54.5\%), while the rest were both CRF02_AG and the other genetic forms; the URFs, therefore, had a higher rate of hypermutation than the subtypes or CRFs. In addition to 11 hypermutated strains, there were 13 strains with major defects likely to make them functionally dead. Most were frame shift mutations leading to stop codons, but there were 3 strains that had large insertions/duplications in 


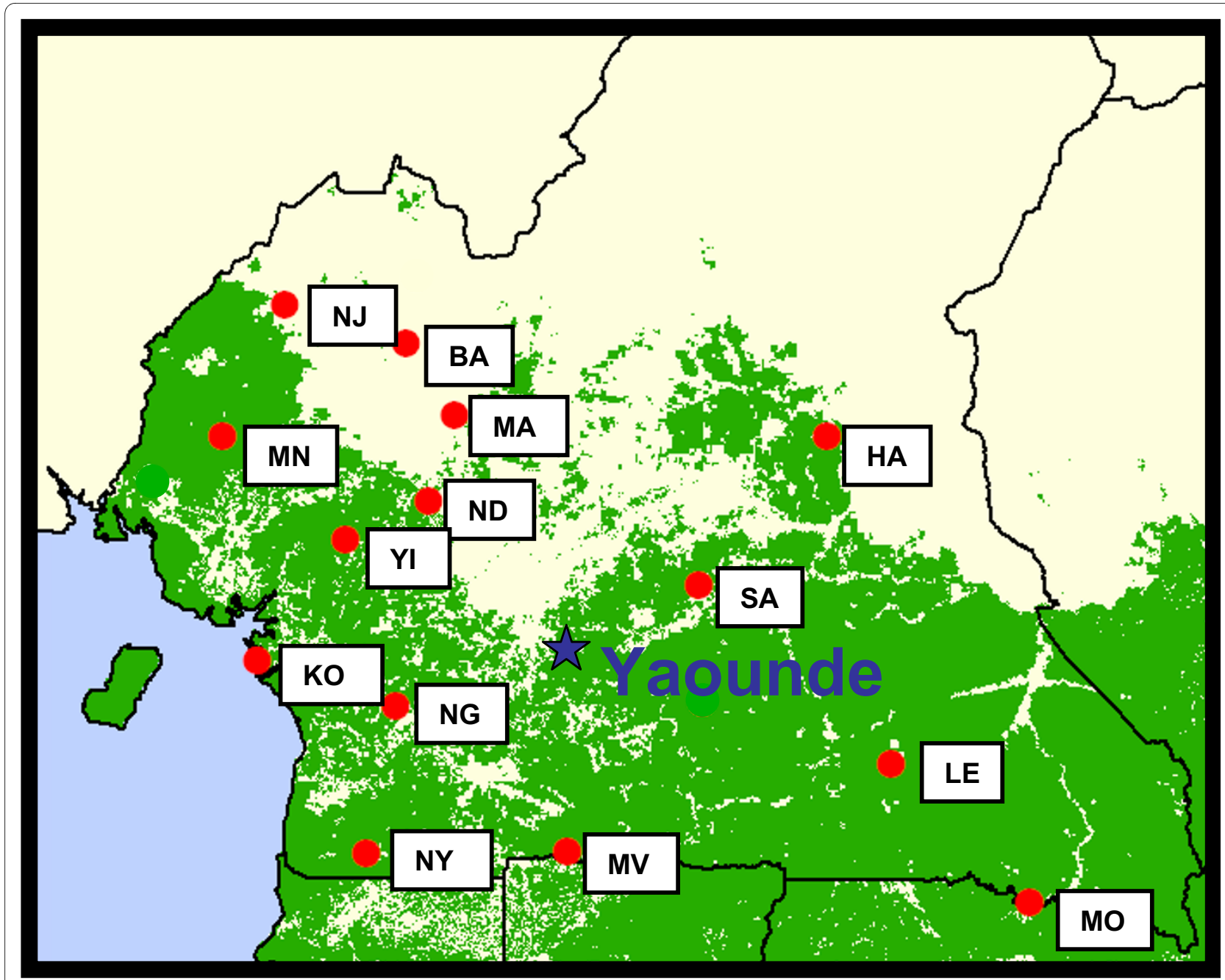

Figure 1 Satellite Map of Cameroon with study sites. Study sites are indicated by the two letter code identifying them.

the nef gene. The sizes of the insertions or duplications were 17 aa, 40 aa and 75 aa, respectively. Defective genomes were not more prevalent in URFs than other genetic forms.

\section{Discussion}

While genetic diversity in Cameroon has been described frequently in the literature, this report documents the high degree of genetic diversity using nearly full genome sequencing of samples from very rural sites in Cameroon. The prevalence of infection was relatively low by African standards (4.9\%), and CRF02_AG was the predominant strain (66.5\%), but about a third of the remaining HIV-1 genotypes detected $(57 / 164)$ were confined to only one or at most a few persons. As others have shown, Central West Africa is the most likely geographical location for the origin for the HIV-1 pandemic [1-3]. However, counter-intuitively, the prevalence of infection there is lower than the newer epidemics to the east, west and south [15].
We hypothesize that the low prevalence is a reflection of lower transmissibility of HIV in these populations. Even in villages with a large number of unique recombinant forms (URF) such as LE, recombinants not only varied in structure but also in the parental strains involved. Only in one village were there 2 URFs with identical structures, probably sex linked; and the two major parental strains for that recombinant (CRF09_cpx, subtype $H$ ) were not even found in the population. Viral loads for these samples revealed no correlation between genetic form (CRF02_AG vs URF, for example) and level of circulating virus (data not shown), but there was a distinct lack of genetically related transmission pairs among the URF from the same village.

A low rate of transmissibility may explain the low prevalence, but it is very difficult to then account for the presence of recombinants with 4 or 5 different subtypes in one strain. Inter-subtype recombinants are generally the result of super-infection with different subtypes and are 


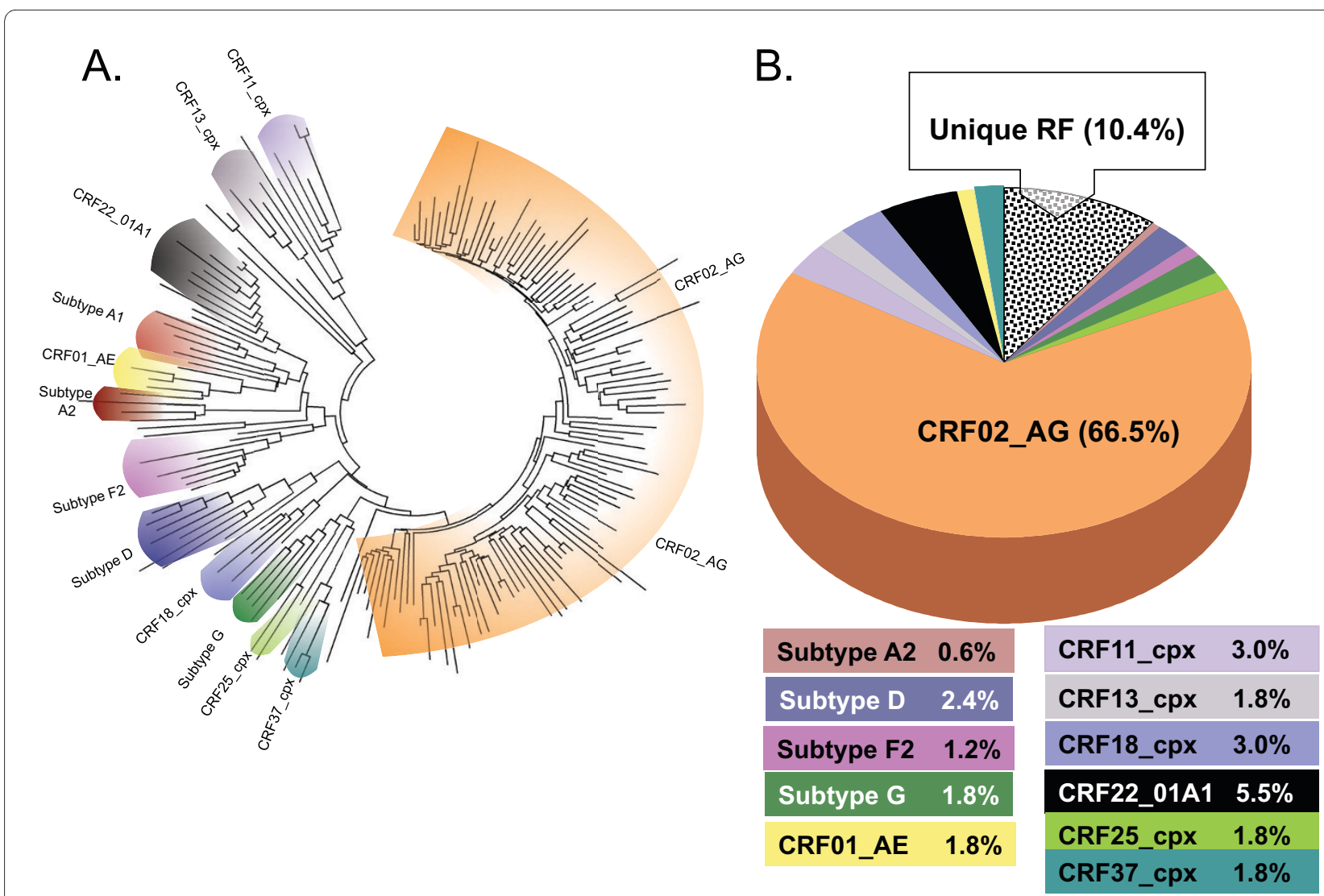

Figure 2 Panel A: Phylogenetic analysis of 164 partial pol sequences from Cameroon. A neighbor-joining analysis of partial pol sequences (protease and the amino terminus of RT) using the Kimura 2-parameter method of distance calculation was performed with representative strains of varying subtypes and CRF (identified by name). The scale bar indicates genetic distance of 1\%. Nodes with significant bootstrap support (>70\%) and containing Cameroon sequences are indicated with color. Panel B: Relative proportions of different subtypes or CRF. RF = recombinant form.

most commonly seen in populations with heavy exposure to multiple subtypes [16,17]. There are multiple subtypes in this population, but at a fairly low level. The hospitalized patients and STD clinic attendees would be expected to have the most risk, and the prevalence of infection among them was significantly elevated compared to the rural villages, but the rate of URFs among them was even lower than in subjects from the rural sites. Recent research among subjects in the capital, Yaounde, found that $16 \%$ of the subjects were dually infected with either 2 different subtypes or different strains from one subtype [9]. As with the subjects in this study, they were low risk. Further study in these populations is needed in order to discover what the mechanism behind this observation might be.

A theoretical model to display one hypothesis is shown in Figure 5, an adaptation from Kalish et al., 2004 [18]. What is known about the origins of HIV put the date of transmission from chimpanzee to human between 18841924, the center of the figure [19]. We hypothesize that the original transmission was probably suboptimal in terms of replication in the human host and that the virus recombined extensively in its 'search' for the right combination of genetic factors. In the figure, this period of time is represented by multiple wavy lines. By 1960 in Kinshasa, there were two identifiable subtypes, or variants capable of epidemic spread, subtype A and subtype B/D $[19,20]$. They were designated as 'pure' subtypes because they were epidemically successful, even though they undoubtedly emerged from a long process of repeated recombination. In most countries in the world, subtypes have been introduced, and in some cases these have recombined to make circulating recombinant forms that are clearly descendants of those subtypes. The situation in Central West Africa is dramatically different from that picture, and we hypothesize that the reason for this is that the viruses still in circulation in rural areas of Cameroon resemble the pre-epidemic viruses, and that they are, in a sense, evolutionary relics. 


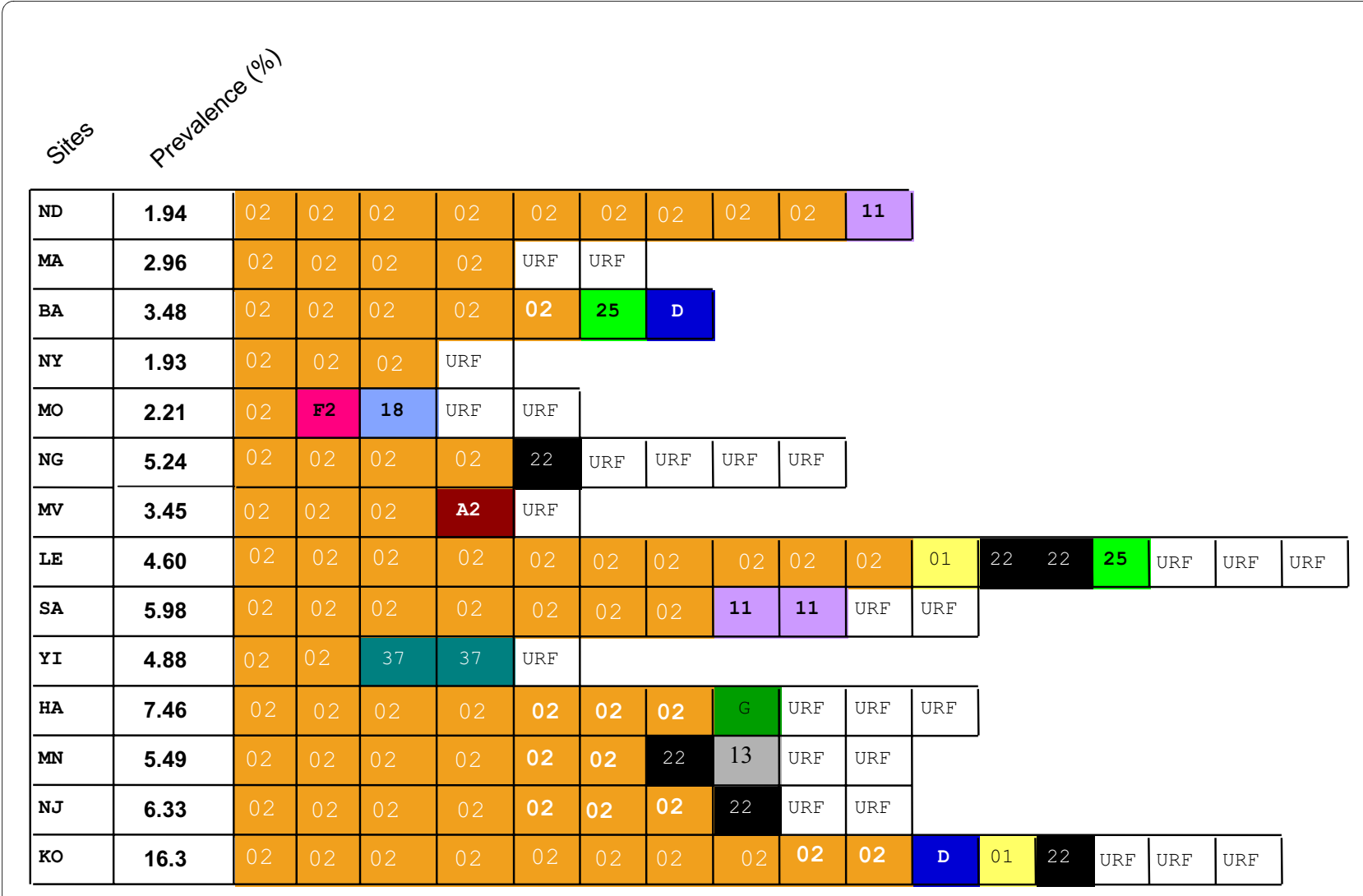

Figure 3 Schematic showing the genetic types of viruses, based on partial pol sequences, by geographic site. Each virus type is represented as a box, with the abbreviated name of the genetic form in the box. The two letter code for the site and the prevalence at the site are on the left. Letters = subtypes; numbers $=$ CRFs.

\section{Conclusions}

The genetic complexity of HIV strains from rural Cameroon defies both logic and experience. Multiply recombinant viruses are found in subjects who have a high risk of superinfection with different strains of HIV, such as commercial sex workers or injecting drug users. The village populations in this study, on the contrary, have a low risk of infection as captured by the prevalence, but harbor viruses having 3 or 4 different parental strains. Among the 78 viruses sequenced in full, there were at least 13 different subtypes, sub-subtypes or CRF represented. It is hypothesized that that this diversity may be due to remnants of the viruses predating the epidemic in 1960 .

\section{Methods}

\section{Subjects}

Of the 17 village sites in Cameroon that were selected for this study, 14 were used for the genetic analysis, shown in Figure 1. In a study approved by the IRB of Johns Hopkins University, participants were healthy adults who gave consent to participate, most of them subsistence farmers and hunters [21]. In addition, in-patients at two district hospitals (Ndikinimeki, Lomie) and outpatients at STI clinics in those same locations were enrolled in the study. Finally, HIV-positive blood was collected from the central blood bank in Yaounde, Cameroon, to monitor genotypes among blood donors. Blood was drawn and plasma and peripheral blood mononuclear cells (PBMC) were separated using CPT blood collection tubes (BD, Inc, Franklin City, NJ). The plasma was tested for HIV antibodies by Ortho HIV-1/HIV-2 Antibody capture ELISA (OrthoClinical Diagnostics, Rochester, NY) and reactive samples were confirmed by two Western Blots (HIV Blot 2.2, Genelabs Diagnostics, Singapore and Calypte, Cambridge Biotech, Cambridge, MA). Those confirmed positive on both were used for viral load determination and DNA extraction. Viral load was measured using the Roche Amplicor HIV-1 monitor test, v. 1.5 (Roche Molecular Systems, Branchburg, NJ). High molecular weight DNA was extracted from the PBMC using QIAmp DNA extraction kits (Qiagen, Valencia, CA).

\section{PCR Amplification}

The DNA from PBMC was amplified by nested PCR in the pol gene producing a $1.1 \mathrm{~kb}$ fragment spanning protease and part of the reverse transcriptase (RT) gene [22]. 


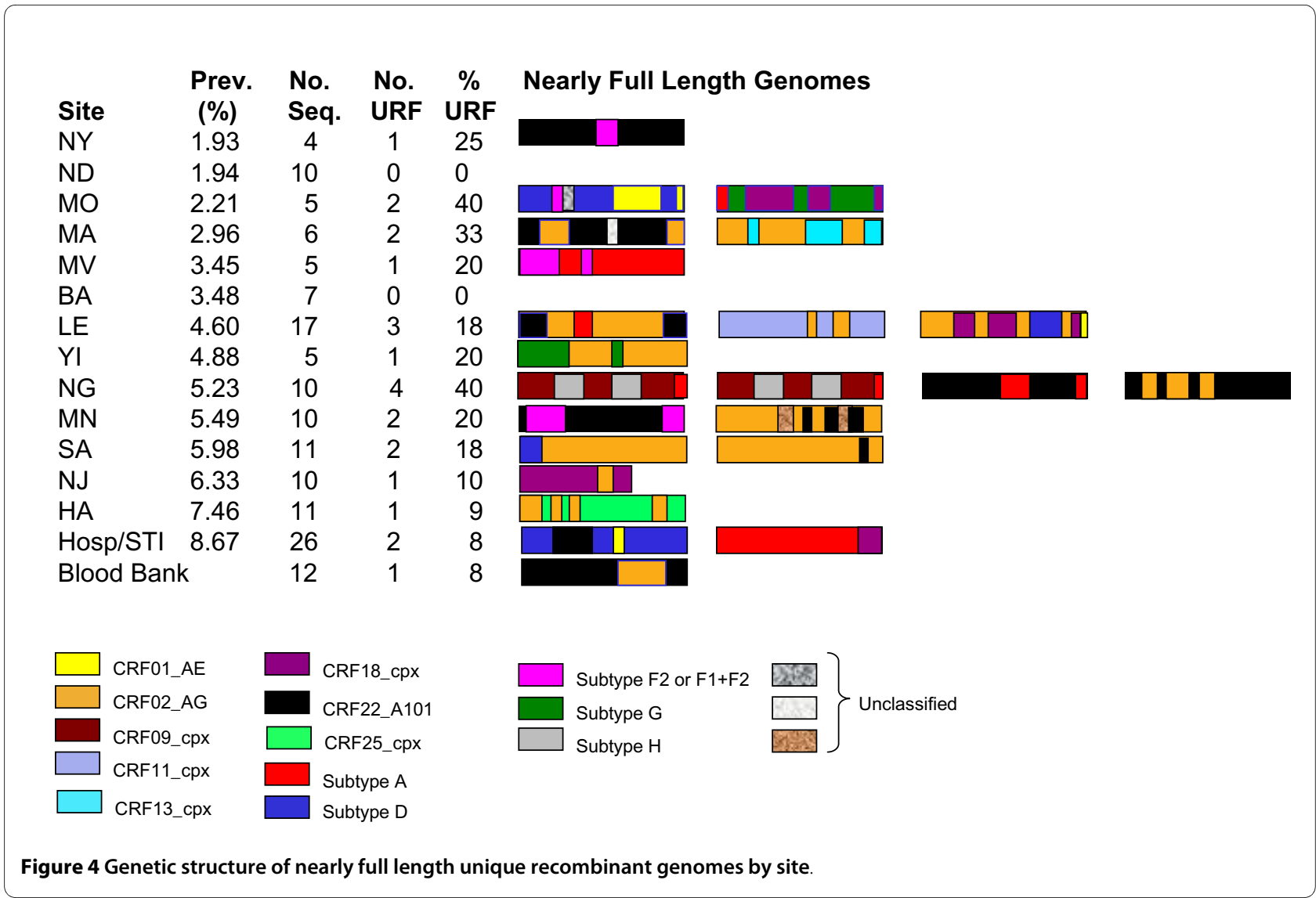

The first and second round reactions were conducted using $8 \mathrm{ml} \mathrm{dNTP}(1.25 \mathrm{mM}), 5 \mathrm{ml} 10 \times$ buffer (no $\mathrm{MgCl}_{2}$ ), $4 \mathrm{ml} \mathrm{MgCl}{ }_{2}(25 \mathrm{mM}), 0.5 \mathrm{ml}$ of each primer $(20 \mathrm{mM}), 0.5$ $\mathrm{ml}$ Ampli Taq gold (Applied Biosystems, Foster City, CA), water and template in $50 \mathrm{ml}$ total reaction volume. First round cycling conditions were: $95^{\circ} \mathrm{C}, 10 \mathrm{~min}$, then 45 cycles of $94^{\circ} \mathrm{C} 30$ seconds, $55^{\circ} \mathrm{C} 30$ seconds, $72^{\circ} \mathrm{C} 1.5 \mathrm{~min}$ utes, then $72^{\circ} \mathrm{C} 7$ minutes. The first round primers were:

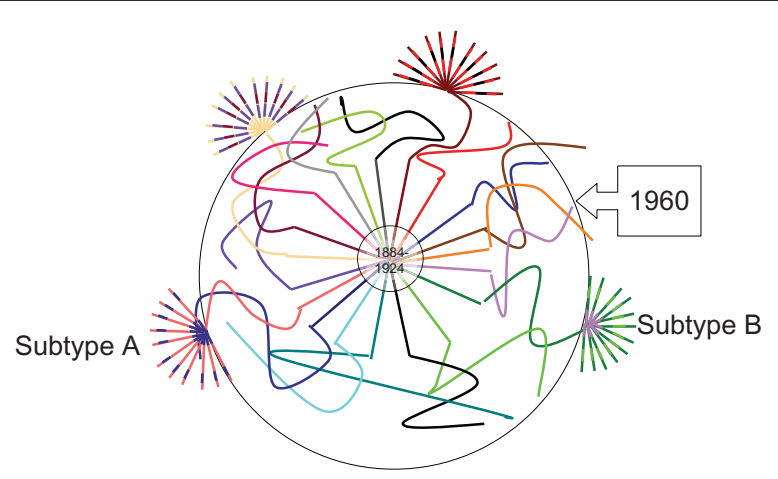

Figure 5 Diagram of a hypothesized scenario of HIV emergence Different colors represent different strains of the virus. Distance from the center of the circle represents time since the initial emergence. Adapted from Kalish et al., 2004 [18].
Pro5F (5'-AGAAATTGCAGGGCCCCTAGGAA) and RT3474R (5'-GAATCTCTCTGTTTTCTGCCAG). The second round reaction was with Pro3F (5'-AGANCAGAGCCAACAGCCCCACCA and ProRT (5'-TTTCCCCACTAACTTCTGTATGTCATTGACA). The cycling conditions were the same except that the annealing temperature was $58^{\circ} \mathrm{C}$ and there were only 30 cycles.

Virtually full-length genomes of HIV-1 were amplified from selected strains based on the results of partial pol sequencing. Limiting template dilution into the first round was performed to decrease the complexity of the sample and allow for direct sequencing of the second round PCR product. The virtually full-length genome was amplified using MSF12b (5'-AAATCTCTAGCAGTGGCGCCCGAACAG) and OFMR1 (5'-TGAGGGATCTCTAGTTACCAGAGTC), followed by F2nst (5'GCGGAGGCTAGAAGGAGAGAGATGG) and ofm19 (5'-GCACTCAAGGCAAGCTTTATTGAGGCTTA).

PCR was performed as described [23,24], using the Expand Long Template kit (Boehringer-Mannheim) and a hot-start method with a melting wax barrier (Dynawax). Cycling conditions were: $94^{\circ}$ for $2 \mathrm{~min}$, then 10 cycles of $94^{\circ} \mathrm{C}$ for $10 \mathrm{~s}, 60^{\circ} \mathrm{C}$ for $30 \mathrm{~s}$ and $68^{\circ} \mathrm{C}$ for $8 \mathrm{~min}$. This was followed by 20 cycles where the annealing temperature was $55^{\circ} \mathrm{C}$. The final extension step was $68^{\circ} \mathrm{C}$ for $10 \mathrm{~min}$. 
Multiple second round PCR amplifications were combined to provide sufficient template for sequencing.

\section{DNA sequencing}

Template DNA for automated sequencing was prepared as described previously [23]. PCR amplification products of the $p o l$ gene and the nearly full-length strains were fully sequenced on both strands by using fluorescent dye terminators and an Applied BioSystems (Applied Biosystems Inc., Foster City, CA) Model 3100 DNA sequencer. DNA sequences were assembled using Sequencher software (Genecodes Inc., Ann Arbor MI) on Macintosh computers. All sequences had at least 2 clear readings in each direction for completion.

\section{Analysis}

A multiple alignment of the Cameroon sequences with selected HIV-1 reference sequences was constructed using MacGDE 1.9.5, software based on Genetic Data Environment (GDE) adapted for Mac OS X $[25,26]$. Gaps that were introduced to create the alignment were eliminated in the final analysis. Reference isolates from the different subtypes and circulating recombinant forms from the pandemic, described in the National HIV Database at Los Alamos, NM, were used to classify the Cameroon sequences http://www.hiv.lanl.gov/. Phylogenetic trees were constructed using the neighbor-joining method and the consistency of branching order was evaluated using bootstrap analysis by MEGA3 software [27]. Genetic relationships can be obscured by the presence of recombinant or novel forms in the analysis of HIV-1 strains. To address this, phylogenetic trees were constructed that included only a few aberrant viral sequences at a time. Hypermutated sequences were identified using Hypermut 2.0 software from the National HIV Database http:// www.hiv.lanl.gov/ and were deleted from appropriate analyses [14].

Recombinant analysis was done with bootscanning [28] and distance scanning [23] using SimPlot software, version 3.5[29]. The nucleotide positions of recombinant breakpoints were designated relative to HXB-2 (GenBank Accession No: K03455). The significance of the breakpoint assignment was assessed by the bootstrap value of the relevant node in the phylogenetic tree, which was $>70 \%$ for significance.

\section{Nucleotide Sequences}

Nucleotide sequence accession numbers of the pol gene sequences from Cameroon are available under GenBank Accession No. AY847362-AY847453. The nearly full length genomic sequences are available under GenBank Accession numbers AY371121- $\underline{\text { AY371170, GQ229529 }}$ and GU201494-GU201517.
Competing interests

The authors declare that they have no competing interests.

\section{Authors' contributions}

JKC supervised analysis and wrote paper. NW developed the study design, supervised sample collection and contributed to the analysis. JT, UT and EM supervised field teams conducting the study in the field and created the database. LE conducted genetic sequencing. DB and FM contributed to study design, laboratory oversight and analysis and DB conceived of the project and contributed at every stage.

\section{Acknowledgements}

NDW was supported by awards from the National Institutes of Health Director's Pioneer Award (Grant DP1-OD000370), the WW Smith Charitable Trust, the US Military HIV Research Program, and grants from the NIH Fogarty International Center (International Research Scientist Development Award Grant 5 K01 TW000003-05), AIDS International Training and Research Program (Grant 2 D 43 TW000010-17-AITRP), and the National Geographic Society Committee for Research and Exploration (Grant \#7762-04). This research was supported in part by the Global Viral Forecasting Initiative, Google.org, and The Skoll Foundation. Thanks to the entire staff of GVFI-Cameroon for their support and assistance. The Cameroon Ministry of Defense, Ministry of Health, and Ministry of Scientific Research and Innovation provided authorizations and support for this work. The authors express many thanks to the editorial assistance of Este Armstrong.

\section{Author Details}

1 Institute of Human Virology, Univ. of Maryland School of Medicine, Baltimore, MD, USA, ${ }^{2}$ Global Viral Forecasting Initiative, San Francisco, and Stanford University, Program in Human Biology, Stanford, CA, USA, 3Faculty of Medicine and Biomedical Sciences, University of Yaounde I, Yaounde, Cameroon, ${ }^{4}$ Chantal Biya International Reference Centre, Yaounde, Cameroon, 5 Hopital Militaire de Yaoundé, Yaounde, Cameroon, ${ }^{6} \mathrm{Global}$ AIDS Program, CDC, Atlanta, GA, USA, ${ }^{7}$ Bill and Melinda Gates Foundation, Seattle, WA, USA and 8University of Pittsburgh Graduate School of Public Health, Pittsburgh, PA, USA

Received: 19 November 2009 Accepted: 28 April 2010

Published: 28 April 2010

\section{References}

1. Sharp PM, Shaw GM, Hahn BH: Simian immunodeficiency virus infection of chimpanzees. J Virol 2005, 79:3891-3902.

2. Van Heuverswyn F, Li Y, Bailes E, Neel C, Lafay B, Keele BF, Shaw KS, Takehisa J, Kraus MH, Loul S, Butel C, Liegeois F, Yangda B, Sharp PM, Mpoudi-Ngole E, Delaporte E, Hahn BH, Peeters M: Genetic diversity and phylogeographic clustering of SIVcpzPtt in wild chimpanzees in Cameroon. Virology 2007, 368:155-171.

3. Keele BF, Van Heuverswyn F, Li Y, Bailes E, Takehisa J, Santiago ML, Bibollet-Ruche F, Chen Y, Wain LV, Liegeois F, Loul S, Ngole EM, Bienvenue Y, Delaporte E, Brookfield JF, Sharp PM, Shaw GM, Peeters M, Hahn BH: Chimpanzee reservoirs of pandemic and nonpandemic HIV-1. Science 2006, 313:523-526.

4. Torimiro J, D'Arrigo R, Takou D, Nanfack A, Pizzi D, Ngong I, Carr JK, Joseph FP, Perno C-F, Cappelli G: Human Immunodeficiency Virus Type 1 Intersubtype Recombinants Predominate in the AIDS Epidemic in Cameroon. New Microbiologica 2009, 32:319-329.

5. Turriziani O, Russo G, Lichtner M, Stano A, Tsague G, Maida P, Vullo V, Antonelli G: Study of the genotypic resistant pattern in HIV-infected women and children from rural west Cameroon. AIDS Res Hum Retroviruses 2008, 24:781-785.

6. Ndembi N, Abraha A, Pilch H, Ichimura H, Mbanya D, Kaptue L, Salata R, Arts EJ: Molecular characterization of human immunodeficiency virus type 1 (HIV-1) and HIV-2 in Yaounde, Cameroon: evidence of major drug resistance mutations in newly diagnosed patients infected with subtypes other than subtype B. J Clin Microbio/ 2008, 46:177-184.

7. Luk KC, Holzmayer V, Ndembi N, Swanson P, Brennan CA, Ngansop C, Mbanya D, Kaptue L, Gurtler L, Devare SG, Hackett J: Near full-length genome characterization of an HIV type 1 CRF25_cpx strain from Cameroon. AIDS Res Hum Retroviruses 2008, 24:1309-1314. 
8. Brennan CA, Bodelle P, Coffey R, Devare SG, Golden A, Hackett J Jr, Harris B, Holzmayer V, Luk KC, Schochetman G, Swanson P, Yamaguchi J, Vallari A, Ndembi N, Ngansop C, Makamche F, Mbanya D, Gürtler LG, Zekeng L, Kaptué L: The prevalence of diverse HIV-1 strains was stable in Cameroonian blood donors from 1996 to 2004. J Acquir Immune Defic Syndr 2008, 49:432-439.

9. Powell RL, Urbanski MM, Burda S, Kinge T, Nyambi PN: High frequency of HIV-1 dual infections among HIV-positive individuals in Cameroon, West Central Africa. J Acquir Immune Defic Syndr 2009, 50:84-92.

10. Njai HF, Gali Y, Vanham G, Clybergh C, Jennes W, Vidal N, Butel C, MpoudiNgolle E, Peeters M, Arien KK: The predominance of Human Immunodeficiency Virus type 1 (HIV-1) circulating recombinant form 02 (CRF02_AG) in West Central Africa may be related to its replicative fitness. Retrovirology 2006, 3:40.

11. Konings FA, Burda ST, Urbanski MM, Zhong P, Nadas A, Nyambi PN: Human immunodeficiency virus type 1 (HIV-1) circulating recombinant form 02_AG (CRF02_AG) has a higher in vitro replicative capacity than its parental subtypes A and G. J Med Virol 2006, 78:523-534.

12. Konings FA, Haman GR, Xue Y, Urbanski MM, Hertzmark K, Nanfack A, Achkar JM, Burda ST, Nyambi PN: Genetic Analysis of HIV-1 Strains in Rural Eastern Cameroon Indicates the Evolution of Second-Generation Recombinants to Circulating Recombinant Forms. J Acquir Immune Defic Syndr 2006, 42:331-341.

13. Carr JK, Torimiro JN, Wolfe ND, Eitel MN, Kim B, Sanders-Buell E, Jagodzinski LL, Gotte D, Burke DS, Birx DL, McCutchan FE: The AG recombinant IbNG and novel strains of group M HIV-1 are common in Cameroon. Virology 2001, 286:168-181.

14. Rose PP, Korber BT: Detecting hypermutations in viral sequences with an emphasis on G --> A hypermutation. Bioinformatics 2000, 16:400-401

15. UNAIDS: HIV/AIDS epidemiological surveillance report for the WHO African Region: 2007 Update. World Health Organization; 2007.

16. Chohan B, Lang D, Sagar M, Korber B, Lavreys L, Richardson B, Overbaugh $\mathrm{J}$ : Selection for human immunodeficiency virus type 1 envelope glycosylation variants with shorter V1-V2 loop sequences occurs during transmission of certain genetic subtypes and may impact viral RNA levels. J Virol 2005, 79:6528-6531

17. Hoelscher M, Dowling WE, Sanders-Buell E, Carr JK, Harris ME, Thomschke A, Robb ML, Birx DL, McCutchan FE: Detection of HIV-1 subtypes, recombinants, and dual infections in east Africa by a multi-region hybridization assay. AIDS 2002, 16:2055-2064.

18. Kalish ML, Robbins KE, Pieniazek D, Schaefer A, Nzilambi N, Quinn TC, St Louis ME, Youngpairoj AS, Phillips J, Jaffe HW, Folks TM: Recombinant viruses and early global HIV-1 epidemic. Emerg Infect Dis 2004, 10:1227-1234.

19. Worobey M, Gemmel M, Teuwen DE, Haselkorn T, Kunstman K, Bunce M, Muyembe JJ, Kabongo JM, Kalengayi RM, Van Marck E, Gilbert MT, Wolinsky SM: Direct evidence of extensive diversity of HIV-1 in Kinshasa by 1960. Nature 2008, 455:661-664.

20. Zhu T, Korber BT, Nahmias AJ, Hooper E, Sharp PM, Ho DD: An African HIV-1 sequence from 1959 and implications for the origin of the epidemic. Nature 1998, 391:594-597.

21. Kijak GH, Sanders-Buell E, Wolfe ND, Mpoudi-Ngole E, Kim B, Brown B, Robb ML, Birx DL, Burke DS, Carr JK, McCutchan FE: Development and application of a high-throughput HIV type 1 genotyping assay to identify CRF02_AG in West/West Central Africa. AIDS Res Hum Retroviruses 2004, 20:521-530.

22. Vinoles J, Serra M, Russi JC, Ruchansky D, Sosa-Estani S, Montano SM, Carrion G, Eyzaguirre LM, Carr JK, Olson JG, Bautista CT, Sanchez JL, Weissenbacher M: Seroincidence and phylogeny of human immunodeficiency virus infections in a cohort of commercial sex workers in Montevideo, Uruguay. Am J Trop Med Hyg 2005, 72:495-500.

23. Carr JK, Laukkanen T, Salminen MO, Albert J, Alaeus A, Kim B, SandersBuell E, Birx DL, McCutchan FE: Characterization of subtype A HIV-1 from Africa by full genome sequencing. AIDS 1999, 13:1819-1826.

24. Salminen MO, Koch C, Sanders-Buell E, Ehrenberg PK, Michael NL, Carr JK, Burke DS, McCutchan FE: Recovery of virtually full-length HIV-1 provirus of diverse subtypes from primary virus cultures using the polymerase chain reaction. Virology 1995, 213:80-86.

25. Linton E: MacGDE v. 2.4. Macintosh Edition 2006.
26. Smith SW, Overbeek R, Woese CR, Gilbert W, Gillevet PM: The genetic data environment an expandable GUI for multiple sequence analysis. Comput Appl Biosci 1994, 10:671-675.

27. Kumar S, Nei M, Dudley J, Tamura K: MEGA: a biologist-centric software for evolutionary analysis of DNA and protein sequences. Brief Bioinform 2008, 9:299-306.

28. Salminen MO, Carr JK, Burke DS, McCutchan FE: Identification of breakpoints in intergenotypic recombinants of HIV type 1 by bootscanning. AIDS Res Hum Retroviruses 1995, 11:1423-1425.

29. Lole K, Bollinger R, Paranjape R, Gadkari D, Kulkarni S, Novak N, Ingersoll R, Sheppard H, Ray S: Full-length human immunodeficiency virus type 1 genomes from subtype C-infected seroconverters in India, with evidence of intersubtype recombination. J Virol 1999, 73:152-160.

doi: $10.1186 / 1742-4690-7-39$

Cite this article as: Carr et al., HIV-1 recombinants with multiple parental strains in low-prevalence, remote regions of Cameroon: Evolutionary relics? Retrovirology 2010, 7:39

\section{Submit your next manuscript to BioMed Centra and take full advantage of:}

- Convenient online submission

- Thorough peer review

- No space constraints or color figure charges

- Immediate publication on acceptance

- Inclusion in PubMed, CAS, Scopus and Google Scholar

- Research which is freely available for redistribution
C) BioMed Central 